\title{
Encephalocraniocutaneous lipomatosis: case report
}

\author{
Juan Pablo Muñoz-Montufar', Jesús Darío Rayo-Mares ${ }^{1}$, Araceli Reyes-Cuayahuitl', \\ Daniel Octavio Pacheco-Rosas ${ }^{2}$ and Mónica Paulina Rangel-Ramírez ${ }^{1}$ \\ ${ }^{1}$ Department of Pediatric Neurology; ${ }^{2}$ Department of Pediatric Infectology, Unidad Médica de Alta Especialidad Hospital de Pediatría Dr. Silvestre
} Freunk Freund, Centro Médico Nacional Siglo XXI, Instituto Mexicano del Seguro Social, Ciudad de México, Mexico

\begin{abstract}
The encephalocraniocutaneous lipomatosis (ECCL), also known as Fishman or Haberland syndrome, is a rare neurocutaneous syndrome of unknown etiology. Clinically characterized by skin, eye and central nervous system lesions. We present the case of a 7-year-old female who presents to the outpatient clinic of Pediatric Neurology because of the presence of seizures detecting clinical and neuroimaging manifestations compatible with ECCL. The objective of this article is to present the case because of its rare presentation and the variety of alterations found in the tomography.
\end{abstract}

KEY WORDS: Lipomatosis encephalocraniocutaneous. Haberland or Fishman syndrome. Nevus psiloliparus. Introduction.

\section{Introducción}

Encephalocraniocutaneous lipomatosis (ECCL), also known as Haberland syndrome or Fishman syndrome, is a rare cutaneous syndrome that characteristically involves ectomesodermal tissue such as the skin, the eyes and the central nervous system (CNS). Classic triad consists of ocular anomalies (nevus psiloliparus, subcutaneous lipomas at the frontotemporal region, hypoplasia or focal dermal aplasia), ocular anomalies (choristomas, colobomas, corneal or anterior chamber abnormalities, and eye globe calcification) and CNS abnormalities (intraspinal lipomas, intracranial vessels' asymmetry, hemispheric atrophy, ventricular dilation, hydrocephalus, arachnoid cysts, porencephalic cysts or calcifications). Most described cases are unilateral; however, there are reports of cases with bilateral involvement ${ }^{1}$.

\section{Case presentation}

We present the case of a 7-year-old girl with no relevant hereditary, family, perinatal or pathological history, with normal psychomotor development and adequate school performance. At birth, a right eye lesion was detected, as well as endotrophy and a fibrous lesion at the edge of the same eye. At 6 months of age she started experiencing focal seizures characterized by eyesight deviation to the right, and treatment with magnesium valproate was therefore initiated.

On physical examination, a zone of alopecia was found at the right frontal region and a fibrous lesion at the external edge (Fig. 1). A normochromic papular lesion of approximately $0.5 \mathrm{~mm}$ was observed on the right cheek (Fig. 2). On the right eye, slow pupillary light reflex, decreased visual acuity and limitation for abduction due to the presence of epibulbar choristoma (Fig. 3). The rest of examination without apparent alterations.

Owing to a previous history of seizures, an electroencephalogram was performed, where asymmetry was found with more amplitude and less frequency in the right parieto-occipital region (Fig. 4).

Plain and contrast cranial tomography showed cortical and subcortical atrophy, Galassi II $4.8 \times 2.3 \mathrm{~mm}$ temporal arachnoid cyst pushing the sphenoid greater

\footnotetext{
Correspondence:

Mónica Paulina Rangel-Ramírez

Circuito de los Parques, 222

Col. El parque de Coyoacán

C.P. 04890, Ciudad de México, México

E-mail: moni_krr@hotmail.com
}

Date of reception: 20-08-2016

Date of acceptance: 08-09-2016

DOI://dx.doi.org/10.24875/GMM.M18000098
Gac Med Mex. 2017;153:833-836

Contents available at PubMed www.gacetamedicademexico.com 


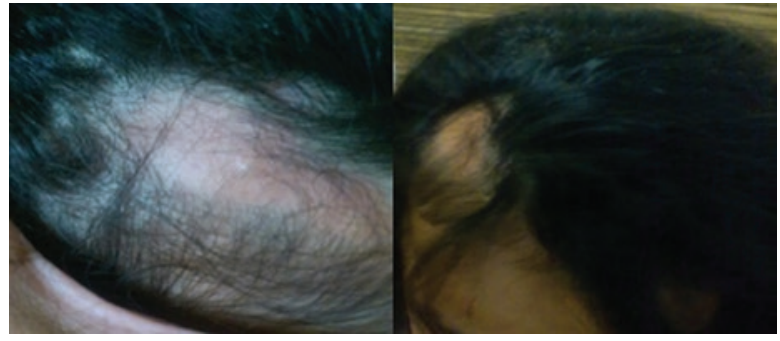

Figure 1. Non-scarring alopecia on the right frontal region.

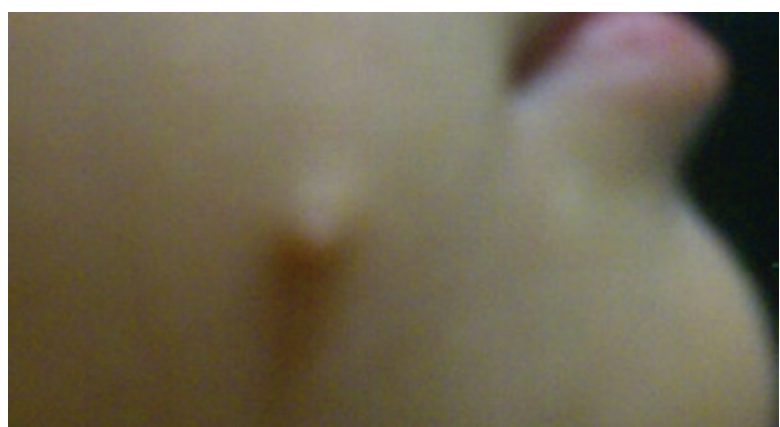

Figura 2. Papular lesion on the right cheek.

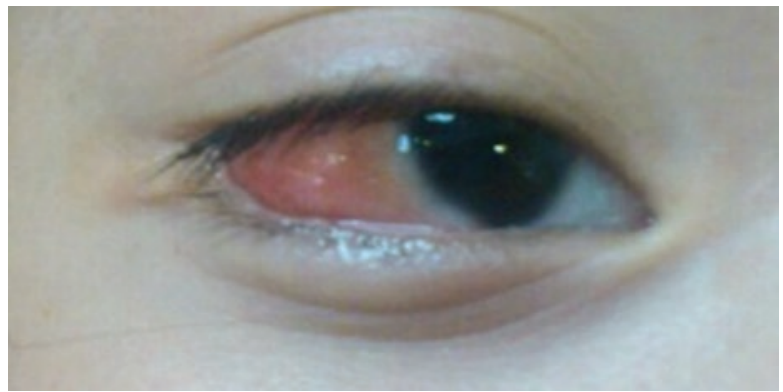

Figure 3. Right eye epibulbar choristoma. wing, parieto-occipital cortical calcifications, $21 \mathrm{x}$ $10.6 \mathrm{~mm}$ right side cerebellopontine angle lipoma, with $-63 \mathrm{UH}$ densities and arterial vessels smaller caliber on the right cerebral hemisphere; none of the lesion was enhanced after contrast administration (Fig. 5).

\section{Discussion}

ECCL (also known as Haberland or Fishman syndrome) is a rare neurocutaneous syndrome, with about 90 cases being found reported in the literature ${ }^{2}$. It was first described by Haberland and Perou in $1970^{3}$, and subsequently Fishman contributed with the description of new cases 4 .

Its etiology is still unknown and, so far, no chromosomal anomalies have been detected; a mosaic probably of an autosomal mutation of a gene involved in the generation of multiple mesenchymal tumors and vasculogenesis has been considered ${ }^{5}$. Pathogenesis is deemed to be cephalic neural crest and anterior neural tube dysgenesis, predominantly affecting ectoderm and mesoderm derivatives ${ }^{6}$.

Clinically, it is characterized by dermal, ocular and CNS lesions. The main dermatological alteration is nevus psiloliparus ${ }^{7}$; also typical is the presence on the same side of the face of normochromic papulonodular lesions of variable size on the forehead, the cheek and the eyelid, which can correspond to lipomas, fibrolipomas, hamartomas or nevi of the connective tissue ${ }^{8,9}$.

The main ocular alteration are choristomas ${ }^{1}$, which are homolateral to the cutaneous lesions and can

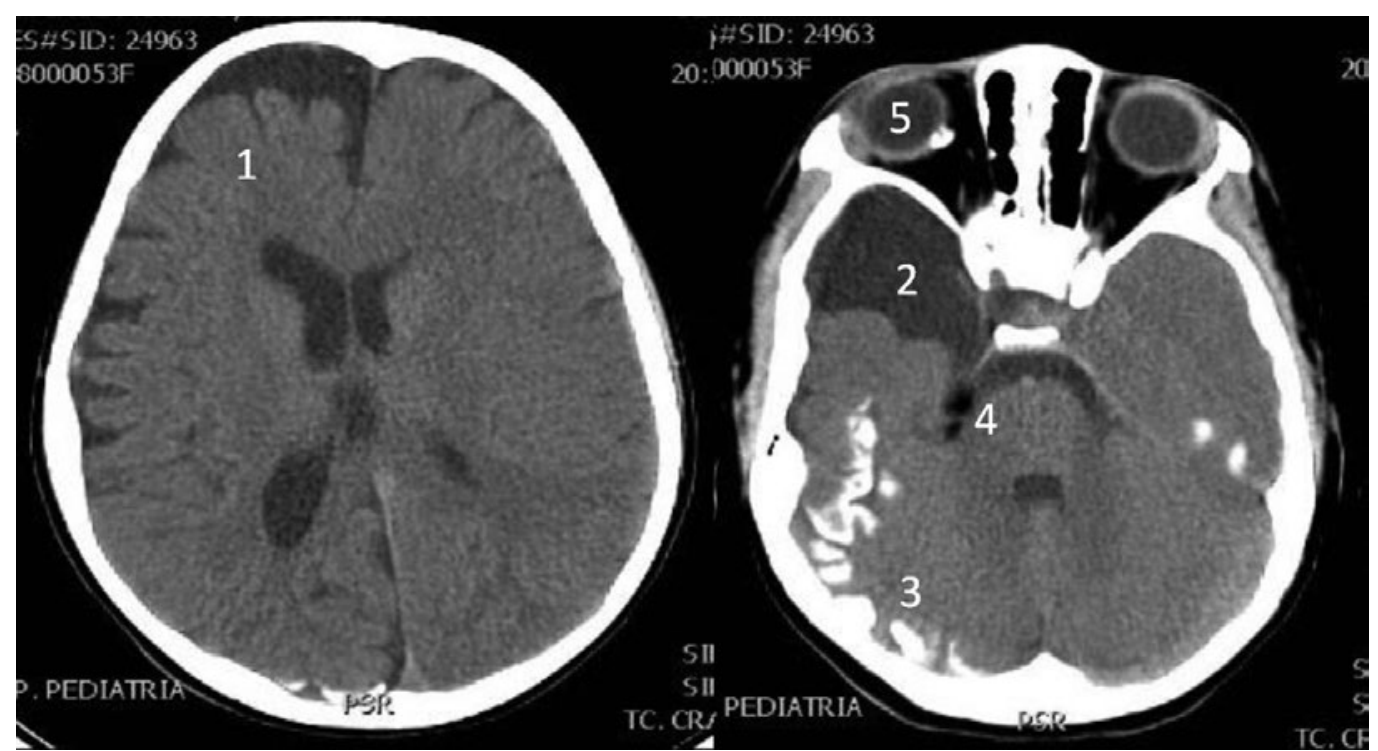

Figure 4. Plain cranial tomography axial planes where right hemiatrophy (1), Galassi II temporal arachnoid cyst (2), cortical parieto-occipital (3), 


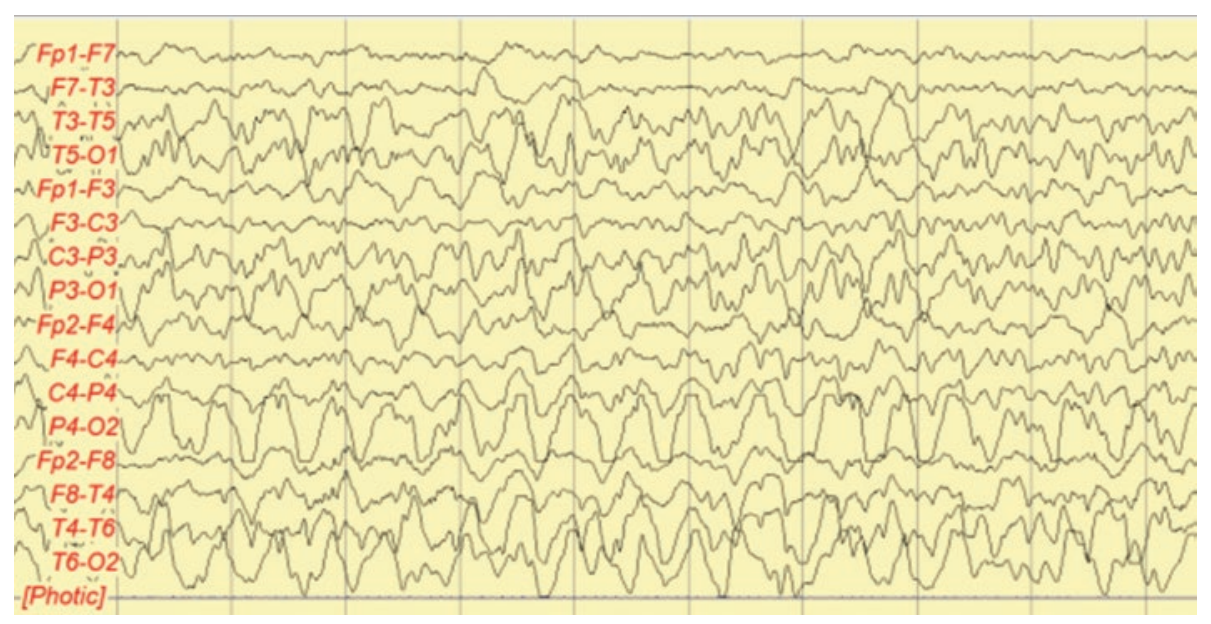

Figure 5. Electroencephalogram where interhemispheric amplitude asymmetry and right occipital delta activity are observed.

cause amblyopia by inducing corneal opacity, refraction defects, or both ${ }^{8,9}$. There may be other anterior chamber anomalies and eye globe calcifications. There are other rarer abnormalities such as papilledema, epicanthus inversus, iris dysplasia and hypotelorism ${ }^{10}$.

Cerebral lesions are localized at the same side as the dermal lesions, and include hemiatrophy, intracranial and medullary lipomas, arachnoid and porencephalic cysts, adjacent ventricular dilation and hydrocephalus. There can also be loss of insular normal operculization and cortical calcifications, lipomas, corpus callosum thinning and vascular lesions (vessel abnormalities and leptomeningeal angiomatosis) $)^{2,8}$. Up to $40 \%$ of patients can experience intellectual disability, and $50-60 \%$ of them have seizures ${ }^{5,11}$, as well as other conditions such as hemiplegia, facial paralysis, spasticity, sensorineural hypoacusis and behavioral disorders ${ }^{12}$.

The diagnosis includes skin lesions biopsy taking, which will demonstrate subcutaneous fat in the reticular dermis. Neuroimaging studies and ophthalmologic examination are indicated. Echocardiogram and electrocardiogram will rule out heart problems. Originally, criteria were proposed by Hunter in $2006^{1}$, and later, in 2009, Moog ${ }^{5}$ performed a review of 54 cases with ECCL diagnosis and established clinical diagnostic criteria (Table 1).

Differential diagnosis of the disease is established with oculoectodermal syndrome, a condition characterized by choristomas, particularly epidermal dermoids and non-scarring alopecia; however, in this condition, the cranial lesion is congenital aplasia cutis, and facial and intracranial lipomas are unusual. Proteus syndrome is a multisystem condition of sporadic onset that can occur also with cutaneous lipomas and ocular choristomas with a mosaic distribution, although this condition is characterized by disproportionate and asymmetric overgrowth especially of the arms, the skull and the external auditory meatus. The characteristic dermal lesion is a connective tissue cerebriform nevus, as well as multiple epidermal nevi, lipomas or lipohiplosia, and vascular malformations. Oculocerebrocutaneous syndrome or Delleman syndrome is characterized by ocular, cerebral and cutaneous congenital anomalies. It is distinguished from ECCL because in Delleman syndrome there is striated muscle hamartoma. In addition, differential diagnosis should be made with other syndromes, such as Schimmelpenning, Goltz and Goldenhar ${ }^{1,9,13}$.

Treatment is symptomatic and, therefore, in case of seizures, anticonvulsants will be indicated. Esthetic surgical treatment can be resorted to for dermal or ocular lesions ${ }^{14}$.

\section{Conclusion}

Haberland syndrome is rare, and there are only about 90 reported cases. ECCL should be considered in the presence of dermal clinical findings such as non-scarring alopecia, papular lesion on the cheek and epibulbar choristoma, as well as when there are radiological findings such as those observed in our patient, including hemiatrophy, arachnoid cysts, intracranial lipoma and cortical and ocular calcification. It is important for this diagnosis to be considered in spite of this being a rare and probably underdiagnosed disease. 
Gaceta Médica de México. 2017;153

Table 1. Moog diagnostic criteria for encephalocutaneous lipomatosis

\begin{tabular}{|c|c|c|c|}
\hline Ocular alterations & Cutaneous alterations & $\begin{array}{l}\text { Central nervous system } \\
\text { alterations }\end{array}$ & Other \\
\hline $\begin{array}{l}\text { Major criteria } \\
\text { 1. Choristoma with or without } \\
\text { associated anomalies }\end{array}$ & $\begin{array}{l}\text { Major criteria: } \\
\text { 1. Confirmed psiloliparus nevus } \\
\text { 2. Possible psiloliparus nevus } \geq 1 \text { of } \\
\text { minor criteria } 2-5 \\
\text { 3. } \geq 2 \text { minor criteria } 2-5\end{array}$ & $\begin{array}{l}\text { Major criteria: } \\
\text { 1. Intracranial lipoma } \\
\text { 2. Intraspinal lipoma } \\
\text { 3. } \geq 2 \text { minor criteria }\end{array}$ & $\begin{array}{l}\text { Major criteria: } \\
\text { 1. Tumor of the jaw (osteoma, } \\
\text { odontoma or ossifying } \\
\text { fibroma) } \\
\text { 2. Multiple bone cysts } \\
\text { 3. Coarctation of the aorta }\end{array}$ \\
\hline
\end{tabular}

Minor criteria:

1. Corneal or anterior chamber anomalies

2. Ocular or palpebral

coloboma

3. Ocular calcification
Minor criteria:

1. Possible psiloliparus nevus

2. Non-scarring irregular

alopecia (withous fatty nevus)

3. Subcutaneous lipoma in the frontotemporal region

4. Focal dermal aplasia or hypoplasia on the scalp

5. Dermal nodular lesions on the eyelids or on external edge or tragus
Minor criteria:

1. Intracranial vascular anomalies, such as angiomas

2. Arachnoid cyst or other meningeal abnormalities

3. Complete or partial hemispheric

atrophy

4. Porencephalic cysts

5. Asymmetric ventricular dilation

or hydrocephalus

6. Calcifications (not on basal

nuclei)

Diagnostic criteria application

Definitive case:

1. Involvement of three systems, two or more major criteria.

2. Involvement of three systems, proven or possible psiloliparus nevus plus one or more minor criteria from 2 to 5 on the skin.

3. Involvement of three systems with one major criterion; one must be proven psiloliparus nevus, or if it is a possible psiloliparus nevus, it should include one or more of criteria 2 to 5 on the skin.

Probable case:

1. Two systems involved with one major criterion on both.

2. Two systems involved plus probable or possible psilolipoarus nevus.

Adapted from Moog U5.

\section{References}

1. Hunter AG. Oculocerebrocutaneous and encephalocraniocutaneous lipomatosis syndromes: blind men and an elephant or separate syndromes? Am J Med Genet. 2006;140:709-26.

2. Moog U, Jones MC, Viskochil DH, et al. Brain anomalies in encephalocraniocutaneous lipomatosis. Am J Med Genet. 2007;143A 2963-72.

3. Haberland C, Perou M. Encephalocraniocutaneous lipomatosis: a new example of ectomesodermal dysgenesis. Arch Neurol. 1970; 22:144-55.

4. Fishman MA, Chang CS, Miller JE. Encephalocraniocutaneous lipomatosis. Pediatrics. 1978;61:580-82.

5. Moog U. Encefphalocraniocutaneous lipomatosis. J Med Genet. 2009; 46:721-9.

6. Koishi GN, Yoshida M, Alonso N, et al. Encephalocraniocutaneous lipomatosis (Haberland's Syndrome) - A case report of a neurocutaneous syndrome and a review of the literature. Clinics. 2008;63:406-8.
7. Happle R, Horster S. Nevus psiloliparus: report of two nonsyndromic cases. Eur J Dermatol. 2004;14:314-6.

8. Brown KE, Goldstein SM, Douglas RS, et al. Encephalocraniocutaneous lipomatosis: a neurocutaneous syndrome. J AAPOS. 2003;7:148-9.

9. Rubegni $P$, Risulo M, Sbano $P$, et al. Encephalocraniocutaneous lipomatosis (Haberland syndrome) with bilateral cutaneous and visceral involvment. Clin Exp Dermatol. 2003;28:387-90.

10. Chittenden HB, Harman HE, Robinson F, et al. A case of encephalocraniocutaneous lipomatosis. Br J Ophtalmol. 2002;86:934-5.

11. Donaire A, Carreno M, Bargalló $N$, et al. Presurgical evaluation and cognitive functional reorganization in Fishman syndrome. Epilepsy Behav. 2005;6:440-3.

12. Chan CC, Chen JS, Chu CY. Haberland syndrome. Dermatol Sin. 2005; 23:41-5.

13. Cohen MM Jr. Proteus syndrome: an update. Am J Med C Semin Med Genet. 2005;137C:38-52.

14. Chandravanshi S. Encephalocraniocutaneous lipomatosis: a case report and review of the literature. Indian J Ophthalmol. 2014;62:622. 